\title{
Zum Problem der Anaphylaxie mit chemisch bekannten Substanzen
}

\section{Doctoral Thesis}

Author(s):

Kleemann, Alois

Publication date:

1939

Permanent link:

https://doi.org/10.3929/ethz-a-000092336

Rights / license:

In Copyright - Non-Commercial Use Permitted 


\title{
Zum Problem der Anaphylaxie mit dhemisch bekannten Substanzen
}

\author{
Von der \\ Eidgenössischen Tedhnischen Hodssdule in Züridh \\ zur Erlangung der \\ Würde eines Doktors der tedhnisden Wissensdhaften \\ genehmigte \\ Promotionsarbeit
}

vorgelegt von

\author{
Alois Kleemann \\ dipl. Ingenieur-Chemiker \\ aus Shönholzerswilen (Thurgau)
}

Referent: Herr Prof. Dr. H. E. Fierz

Korreferent: Herr Prof. Dr. L. Ruzidka

BASEL

Buchdrudkerei E. Birkhäuser \& Cie,, A. G.

1939 


\section{Zusammenfassung.}

I. 1. Bei mit Succinanilsäure-azo-protein vorbehandelten Meerschweinchen konnten wir mit Bis-p-succinanilsäure-azo-resorcin F im Schultz-Dale'schen Versuch gelegentlich den anaphylaktischen Schock auslösen. Das ist eine Bestätigung der Versuche von Landsteiner und van der Scheer ${ }^{1}$ ).

2. Bei mit Succinanilsäure-azo-protein vorbehandelten und sicher sensibilisierten Meerschweinchen konnten wir häufig mit Bis-p-succinanilsäure-azo-resorcin F keinen anaphylaktischen Schock auslösen, wohl aber die spezifische Überempfindlichkeit neutralisieren. Das ist eine Bestätigung unserer früherenVersuche ${ }^{2}$ ).

3. Die Resultate, wie sie unter I. 1. und I. 2. zusammengefasst wurden, wurden unter anscheinend identischen Versuchsbedingungen erzielt.

II. Oleyl-N-methyltaurin bewirkte auch bei Normaltieren, allerdings seltener als bei vorbehandelten, eine neutralisierbare Kontraktion des überlebenden Uterus ${ }^{3}$ ).

III. 1. Die früher festgestellten Unterschiede zwischen Bis-p-succinanilsäure-azo-resorcin $\mathrm{L}^{1}$ ) und Bis-p-succinanilsäure-azo-resorcin $\mathrm{F}^{2}$ ), die nach verschiedenen Methoden hergestellt wurden, beruhen auf Stellungsisomerie. Der' erstere ist ein 4,6 -, der zweite ein 2,4-Resorcindisazofarbstoff.

2. Das bei $180^{\circ}$ schmelzende Acetylderivat von 4,6-Diaminoresorcin ist das Hexa-acetyl-4,6-diamino-resorcin.

3. Es wurde Tetra-acetyl-p-phenylendiamin hergestellt, das bei $207^{\circ}$ schmilzt.

4. Es wurde aus reinem 2,4-Diamino-resorcin-dichlorhydrat durch Acylieren und anschliessende trockene Destillation ein .Dimethyl-benzo-dioxazol erhalten, das bei $111^{\circ}$ schmilzt. Das in der Literatur beschriebene, auf gleiche Weise gewonnene Produkt zeigt allerdings einen Smp. von $192^{\circ 4}$ ).

Für finanzielle Unterstützungen unserer Arbeiten danken wir der Chemischen Fabrik Sandoz A. G. aufs beste.

1) Landsteiner und van der Scheer, J. Expl. Med. 56, 399 (1932); 57, 633 (1933).

2) H. E. Fierz, W. Jadassohn und Zürcher, Helv. 20, 16 (1937).

3) Vgl. H. E. Fierz, W. Jadassohn und A. Margot, Helv. 21, 280 (1938).

4) Henrich und Roedel, B. 54, 2501 (1921). 